\title{
Percutaneous kyphoplasty assisted with/ without mixed reality technology in treatment of OVCF with IVC: a prospective study
}

Peiran Wei, Qingqiang Yao, Yan Xu, Huikang Zhang, Yue Gu and Liming Wang*

\begin{abstract}
Background: The purpose of this study was to assess the clinical outcome of percutaneous kyphoplasty (PKP) assisted with mixed reality (MR) technology in treatment of osteoporotic vertebral compression fracture (OVCF) with intravertebral vacuum cleft (IVC).

Method: Forty cases of OVCF with IVC undergoing PKP were randomized into a MR technology-assisted group (group A) and a traditional C-arm fluoroscopy group (group B). Both groups were performed PKP and evaluated by VAS scores, ODI scores, radiological evidence of vertebral body height, and kyphotic angle (KA) at pre-operation and post-operation. The volume of injected cement, fluoroscopy times, and operation time were recorded. And cases of non-PMMA-endplates-contact(NPEC) in radiological evidence was also recorded postoperatively. The clinical outcomes and complications were evaluated afterwards. All patients received 10 to 14 months follow-up, with an average of 12 months.
\end{abstract}

Result: This MR-assisted group (group A) acquired more about the amount of the polymethyl methacrylate (PMMA) injection and postoperative vertebral height and less about postoperative KA, fluoroscopy times, and operation time compared with the control group (group B) $(P<0.05)$. The VAS scores and ODI scores in both groups have improved, but more significantly in group $A(P<0.05)$. Also, more cases achieve both-endplates-touching of cement in group $A(P<0.05)$. And there are less of the loss of vertebral height, KA, and occurrence of re-collapse of the vertebra in group A during the follow-up $(P<0.05)$.

Conclusion: PKP assisted with MR technology can accurately orientate the position of IVC area, which can be augmented by the balloon leading to more satisfied vertebral height improvement, cement diffusion, and pain relief.

Trial registration: ClinicalTrials.gov Identifier: NCT03959059. Registered 25 September 2016.

Keywords: Mixed Reality, PKP, IVC, OVCF

\footnotetext{
* Correspondence: wlmnjyy@126.com

Department of Orthopaedics, Nanjing First Hospital, Nanjing Medical

University, No. 68 of ChangLe Road, Nanjing 210029, Jiangsu Province, China
}

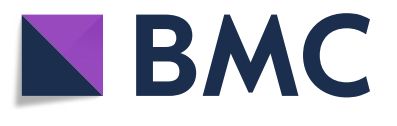

(c) The Author(s). 2019 Open Access This article is distributed under the terms of the Creative Commons Attribution 4.0 International License (http://creativecommons.org/licenses/by/4.0/), which permits unrestricted use, distribution, and reproduction in any medium, provided you give appropriate credit to the original author(s) and the source, provide a link to the Creative Commons license, and indicate if changes were made. The Creative Commons Public Domain Dedication waiver (http://creativecommons.org/publicdomain/zero/1.0/) applies to the data made available in this article, unless otherwise stated. 


\section{Key points}

1. Destruction of membrane at the periphery of the IVC is probably the key point for distribution of cement to be interdigitated with the surrounding cancellous bone for the sake of better clinical efficacy.

2. The location of IVC in the vertebral body could be accurately acquired preoperatively from the CAD virtual anatomic images obtained by fusion of MRI and three-dimensional CT images, which was a great advantage for the guidance.

3. PKP assisted with MR technology could acquire real-time and accurate guidance to the IVC area during operation.

\section{Background}

Percutaneous kyphoplasty (PKP) is an effective and currently widely used method for the treatment of osteoporotic vertebral compression fracture (OVCF), the procedure was done usually under local anesthesia, and the patient was well tolerated [1]. Early studies have shown that patients could obtain promising clinical outcome of immediate pain relief and functional improvement, especially among the elderly [2-6]. However, there is still a very number of patients who were unsatisfied with the result after operation. As for these patients, they complain about their unsatisfied or unchanged pain relief or even worse pain, which may indicate continued compression or a recurrent fracture in the treated vertebra. Previous studies have shown that intravertebral vacuum cleft (IVC) in acute OVCF was not a rare phenomenon [7-10] and it also has been considered as an important risk factor for persistent back pain and severe vertebral collapse and might be the main reason responsible for unsatisfied outcome after PKP $[11,12]$. On magnetic resonance imaging (MRI), an IVC presents linear or cystic hypointensity similar to air on T1-weighted sequences and hyperintensity similar to cerebrospinal fluid on T2-weighted sequences $[13,14]$. It also has been demonstrated $[15,16]$ that during the PKP procedure, instead of diffusing into the surrounding cancellous bone, the cement was formed into a solid lump that causes the fibrocartilaginous membrane at the periphery of IVC inhibited its dispersion. The fibrocartilaginous membrane can be broken by the balloon injected into the IVC area, leading to improvement of the cement diffusion $[17,18]$. Therefore, in order to break the fibrocartilaginous membrane of IVC by the balloon during PKP procedure, so as to make the cement sufficiently diffuse into surrounding cancellous bone, we attempted to acquire accurate navigation to the IVC area.
Mixed reality (MR) is a combination of VR and AR in 3D applications [19], and it divorces digital reality and virtual digital images from the virtual world on the screen, so that three-dimensional virtual objects and the real world can be accurately combined [20,21]. Previous studies have reported that MR technology has been used to show three-dimensional reconstructed model of all aspects, both preoperatively and intraoperatively; the muscles, blood vessels, and bones could be accurately seen; and the anatomical data could be measured [22]. Thus, it could help the surgeon to select the best operative program individually and precisely [21]. Under this technology, the real tissues and preoperative image data can be matched and fused to achieve real-time three-dimensional visual positioning and real-time display of the position of surgical tools, so as to carry out surgical navigation [23, 24]. The purpose of the present study was to evaluate PKP assisted with precise navigation by MR technology in the treatment of OVCF with IVC.

\section{Methods \\ Patients}

All patients participated in the trial and signed informed consent voluntarily. There was also no financial relationship between the investigators and study participants. Patients were required to meet the following inclusion criteria: (1) single-level OVCF in the thoracic and lumbar levels (T10-L4) [25], suffering with severe back pain, and (2) OVCF without damaged vertebral posterior wall and nerve lesion; (3) the patient age was more than 50 years old, and diagnosis of osteopenia or osteoporosis was confirmed by bone densitometry; and (4) all patients underwent plain radiography, computed tomography (CT), and MRI before surgery, with IVC presented in MRI. From June 2017 to September 2017, there were 40 patients who met the criteria above; who participated the trial, aging from 50 to 95 years old; and were randomized into MR technology-assisted group (group A) and traditional C-arm fluoroscopy group (group B), 20 cases for each group.

Approval was obtained from the Institutional Review Board of Nanjing First Hospital prior to performing the study.

\section{Assessment of clinical parameters}

Several parameters including age, sex, and bone mineral density (BMD) of the two groups have been evaluated preoperatively. Operation duration, fluoroscopy times, and volume of cement injected to both groups were recorded respectively. Symptoms of two groups were evaluated by visual analog scale (VAS) score of back pain and Oswestry Disability Index (ODI) of movement function. Immediate postoperative, 1-, 3-, 6 months, and 1 year VAS and ODI scores were compared. 


\section{Assessment of radiological parameters}

We measured preoperative and postoperative (1 day, 1-, $3-, 6$ months, and 1 year) radiological parameters including kyphotic angle (KA) from sagittal radiographs, and anterior, central, and posterior vertebral height; anterior/ posterior height ratio was defined as relative anterior vertebral height, and central/posterior height ratio was defined as relative central vertebral height (Fig. 1a). Kyphotic angle (KA) was formed by the upper and lower endplates of the fractured vertebral body (Fig. 1b). Patients underwent CT scanning pre- and postoperatively (Fig. 1d, f). IVC was presented in MRI image (Fig. 1e). And cases of cement touching both endplates in each of the two groups were recorded postoperatively (Fig. 1c). In group $\mathrm{A}$, patients also required accurate three-dimensional images to confirm the location of IVC in the vertebral body, which was obtained by computer-aided design (CAD) of preoperative MRI and three-dimensional CT images, for the purpose of navigation by MR technology (Fig. 2).

\section{Surgery}

All of the surgeries were performed by one group of surgeons and adopted bipedicular approach in a prone posture under local anesthesia ( $1 \%$ lidocaine) in all cases.

Group A: All the PKP operations were performed by one group of surgeons. Persons were in the prone position with local anesthesia (1\% lidocaine), through bilateral transpedicle puncture approach. Cases in
MR-PKP group (group A) underwent dual-source 64slice CT volume scanning (Siemens Sensation, Germany) with a slice thickness of $1 \mathrm{~mm}$ and a scanning matrix of $512 \times 512$. Input the data obtained into the M3D digital medical software (Bahulu, Shanghai Front Computing Company, China); hence, the three-dimensional model was obtained by using its threshold segmentation and regional growth functions. The responsible vertebral body and adjacent vertebral body were labeled with different colors, the location and direction of pedicle insertion were predesigned, and the three-dimensional virtual digital CAD image was constructed (Fig. 2). Before the operation, the CAD image was imported into the computer of MR system (Medivi, Changzhou, China). Doctors wore AR glasses HoloLens (Microsoft, USA). As the original data for $\mathrm{CT}$ reconstruction was taken in supine position, the patient is placed in prone position during operation. We need C-arm fluoroscopy during operation to adjust the CAD image to optimally match the patient in prone position. X-ray fluoroscopy was performed, and the spatial registration of virtual image and patient's body was completed by manual positioning. With MR technology and $\mathrm{C}$-arm fluoroscopy, these 3D virtual images can be accurately combined with the patient, so the surgeon could see the spinal $3 \mathrm{D}$ virtual images (CAD images) accurately in the patient's body. Through this combination of virtual images and real body, also combined with $\mathrm{C}$-arm fluoroscopy, needles were

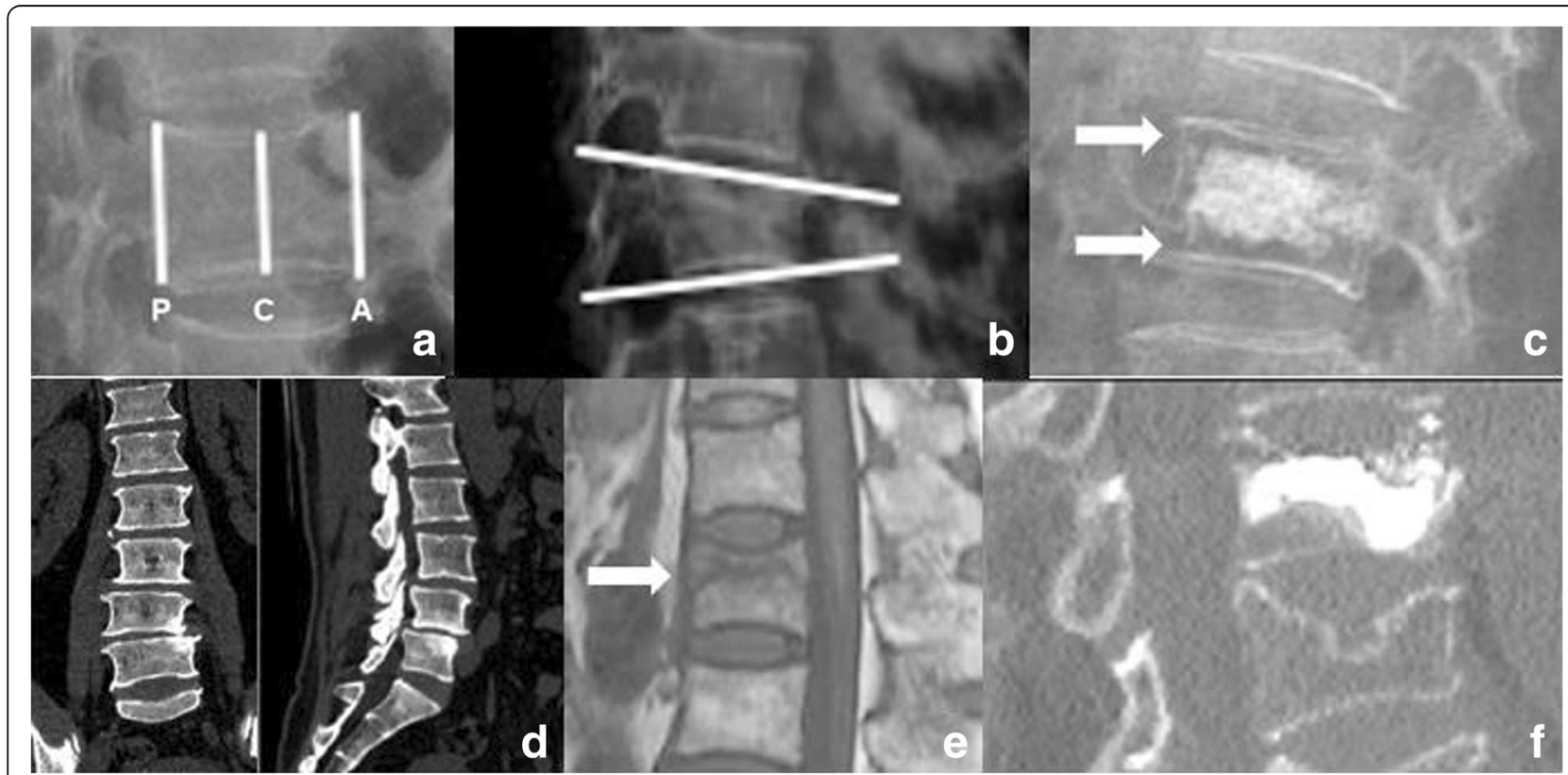

Fig. 1 a (A): anterior vertebral height, $(C)$ : central vertebral height, $(P)$ : posterior vertebral height. b Kyphotic angle (KA). c Cement non-contact both endplates (NPEC). $\mathbf{d} C T$ images. e MRI image of OVCF with IVC. $\mathbf{f}$ Postoperative CT images, some part of the vertebra is not filled with cement 

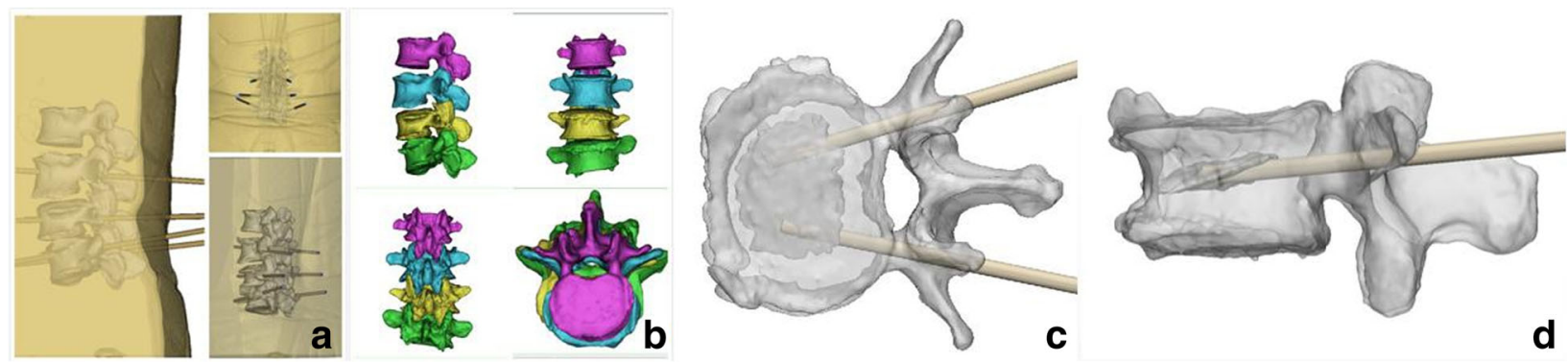

Fig. 2 a-d CAD virtual anatomic images and the position of IVC in the merged images of reconstructed vertebra

accurately inserted through bilateral pedicle of the injured vertebra until the tip was optimally positioned in the IVC. Then the needles were removed from the trochar, and a balloon was placed into the channel and inflated in order to augment the IVC area, elevate the endplate, and restore the height of the vertebral body. Cement (poly methyl methacrylate, PMMA) was injected into the IVC area for attempting to make the cement to be sufficiently interdigitated with the surrounding cancellous bone and complete filling of the cleft, maximizing the stabilization of the IVC and fracture (Fig. 3).

Group B: Insertion of the transpedicular access was performed bilaterally under $\mathrm{C}$-arm fluoroscopic guidance. Combined with the X-ray, CT, MRI images preoperatively and the $\mathrm{C}$-arm fluoroscopic images, the tip of needle was set to the most possible area of the IVC, the needle was removed and a balloon was inserted to the position, which was inflated and expanded to restore the height of the vertebra, and then the cement (PMMA) was injected. The filling and diffusion of bone cement were observed while injection was carried out. And the injection was stopped when the bone cement reached the posterior edge of the vertebral body.

\section{Statistical analysis}

SPSS V.11.0 statistical software was used for analysis. Comparisons were made before and at each postoperative follow-up appointment. Qualitative characteristics of groups were assessed using one-way or repeated

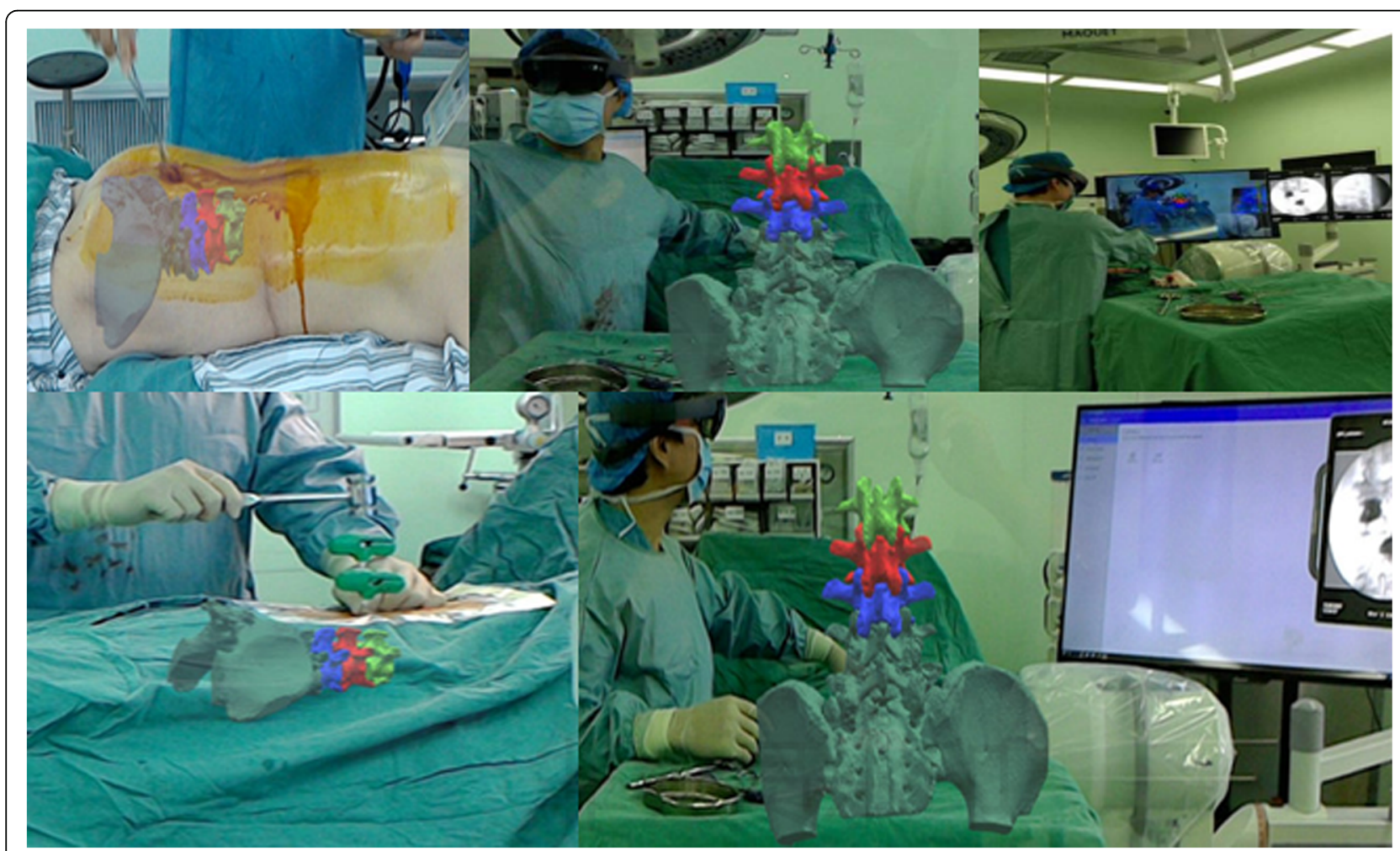

Fig. 3 Procedures of PKP with MR technology and CAD virtual anatomic images 
measures ANOVA and $t$ test. $\chi^{2}$ tests were performed for categorical variables. $P<0.05$ was considered statistically significant.

\section{Results}

Forty patients (M/F 13:27) were randomly categorized into two groups, each group with 20 cases. The mean age of the patients was $73.48 \pm 8.72$ years in group A and $74.02 \pm 8.85$ years in group $B$, and the length of follow-up ranged from 10 to 14 months (median 12 months). There was no significant difference between the two groups in baseline parameters including age, sex, BMD, VAS, ODI, vertebral height, KA, level of injured vertebra, and the time from injury to surgery $(P>0.05$, Table 1$)$.

The operation duration and fluoroscopy times in group A were less than those in group $\mathrm{B}(P<0.05)$. The amount of PMMA injection during MR guidance (group A) was more than that during $\mathrm{C}$-arm fluoroscopic guidance (Table $2, P<0.05$ ).

The postoperative VAS and ODI scores were followed about 1 year. Immediately after surgery, the mean VAS and ODI scores of all patients in both of the two groups

Table 1 Basic characteristics and preoperative data of the two

\begin{tabular}{|c|c|c|c|}
\hline Patient characteristics & Group A & Group B & $P$ \\
\hline Age (years) & $73.48 \pm 8.72$ & $74.02 \pm 8.85$ & 0.97 \\
\hline Women, $n(\%)$ & $14(70 \%)$ & $13(65 \%)$ & 0.77 \\
\hline BMD score & $-4.35 \pm 0.94$ & $-4.44 \pm 0.76$ & 0.89 \\
\hline VAS scores & $8.38 \pm 1.28$ & $8.14 \pm 1.35$ & 0.31 \\
\hline ODI scores & $83.95 \pm 8.96$ & $84.27 \pm 7.48$ & 0.13 \\
\hline Relative anterior vertebral height (\%) & $77.51 \pm 5.91$ & $75.72 \pm 6.73$ & 0.79 \\
\hline Relative central vertebral height (\%) & $56.74 \pm 4.13$ & $58.28 \pm 3.62$ & 0.96 \\
\hline KA $\left({ }^{\circ}\right)$ & $14.02 \pm 4.06$ & $12.78 \pm 4.75$ & 0.39 \\
\hline \multicolumn{4}{|c|}{ Time from injury to surgery (number of patients) } \\
\hline 1 day & 0 & 1 & 0.97 \\
\hline 2 days & 0 & 1 & \\
\hline 3 days & 15 & 14 & \\
\hline 4 days & 2 & 2 & \\
\hline 5 days & 3 & 2 & \\
\hline \multicolumn{4}{|c|}{ Level of injured vertebra (number of patients) } \\
\hline T10 & 1 & 1 & 0.66 \\
\hline T11 & 1 & 1 & \\
\hline $\mathrm{T} 12$ & 5 & 6 & \\
\hline L1 & 6 & 7 & \\
\hline L2 & 4 & 3 & \\
\hline L3 & 2 & 2 & \\
\hline L4 & 1 & 0 & \\
\hline
\end{tabular}

decreased significantly $(P<0.05)$, but the scores decreased more in group A $(P<0.05)$. However, we observed a gradual significant increase in VAS and ODI scores during the 1-year follow-up after surgery in group $B$. The VAS and ODI scores were significantly higher in group B than those in group A at the 1-year postoperative follow-up $(P<0.05)$. The VAS and ODI scores in group $B$ immediately after surgery were $2.58 \pm 1.09$ and $29.11 \pm 8.07$, respectively, and increased to $3.42 \pm 1.16$ and $35.07 \pm 9.1$ at 1 year, respectively (Tables 2 and 3 ).

Vertebral height was defined as relative anterior vertebral height (anterior/posterior height ratio) and relative central vertebral height (central/posterior height ratio). $\mathrm{KA}$ and preoperative reduction in height of the vertebra were not significantly different in the two groups $(P>$ $0.05)$. However, postoperative height of the vertebra (relative anterior height, relative central height) was significantly taller in group A than in groups B (Table 2, $P$ $<0.05)$. Vertebral kyphotic angle (KA) in group A was also significantly lower than that in group B (Table 2, $P$ $<0.05)$. Cases of cement-both-endplates-contact were 13 in group A and 5 in group B, which was significantly different $(P<0.05)$ (Tables 2 and 3$)$.

\section{Complications}

No cement leakage, neurologic deficits, re-fracture of the treated vertebra, and other complications were observed in these two groups. There was one case of adjacent vertebral fracture in group $B$, while none in group A. The perioperative mortality was $0 \%$.

\section{Discussion}

IVC in the fractured vertebra has been reported to be the main reason to intractable pain of OVCF and unsatisfied pain relief after PKP [26]. And IVC may cause pseudarthrosis of the vertebra leading to spinal instability, which may give rise to the severe chronic pain. Therefore, it was thought to be a good indication for PKP to acquire pain relief and spinal stabilization through filling IVC with cement. However, Heo et al. [15] found that the cement cannot be diffused to be interdigitated with the surrounding cancellous bone because of the inhibition by the fibrocartilaginous membrane of IVC. It formed into a solid lump which may induce greater stress to the surrounding cancellous bone, leading to recollapse or refracture [15, 18, 27]. It has been reported that distribution of the cement is more important than the volume injected, specifically acquiring the cement touching both endplates may be more crucial for stabilization of the compression fracture [28-31]. Both the superior and inferior endplates should be touched with cement to provide complete support of the vertebra to prevent continuing collapse and recurrent fractures [9, 11, 32-34]. Biomechanical 
Table 2 Postoperative data of the two groups

\begin{tabular}{|c|c|c|c|}
\hline & Group A & Group B & $P$ \\
\hline Operative time (min) & $25.12 \pm 5.36$ & $45.14 \pm 3.86$ & $<0.05$ \\
\hline Fluoroscopy times & $31.87 \pm 9.77$ & $76.94 \pm 8.65$ & $<0.05$ \\
\hline Amount of cement injection (ml) & $6.41 \pm 0.54$ & $4.22 \pm 0.35$ & $<0.05$ \\
\hline Cases of cement of both-endplates-contact & 13 & 6 & $<0.05$ \\
\hline Relative anterior vertebral height (\%) & $92.42 \pm 5.14$ & $71.21 \pm 4.83$ & $<0.05$ \\
\hline Relative central vertebral height (\%) & $79.74 \pm 3.92$ & $60.53 \pm 3.31$ & $<0.05$ \\
\hline Improvement of relative anterior vertebral height (\%) & $12.81 \pm 4.76$ & $6.94 \pm 3.42$ & $<0.05$ \\
\hline Improvement of relative central vertebral height (\%) & $19.71 \pm 2.82$ & $3.42 \pm 3.57$ & $<0.05$ \\
\hline KA $\left(^{\circ}\right)$ & $7.11 \pm 3.01$ & $10.89 \pm 2.91$ & $<0.05$ \\
\hline Change of KA $\left(^{\circ}\right)$ & $7.11 \pm 1.21$ & $3.72 \pm 1.53$ & $<0.05$ \\
\hline
\end{tabular}

Table 3 VAS and ODI scores and imaging parameters during 1 year follow-up

\begin{tabular}{|c|c|c|}
\hline & Group A & Group B \\
\hline \multicolumn{3}{|l|}{ VAS } \\
\hline Immediate postoperative & $1.37 \pm 1.01$ & $2.58 \pm 1.09$ \\
\hline 1 month & $1.33 \pm 1.03$ & $2.96 \pm 1.15$ \\
\hline 3 month & $1.39 \pm 1.04$ & $3.17 \pm 1.20$ \\
\hline 6 month & $1.36 \pm 1.08$ & $3.21 \pm 1.08$ \\
\hline 12 month & $1.31 \pm 1.12$ & $3.42 \pm 1.16$ \\
\hline \multicolumn{3}{|l|}{ ODI } \\
\hline Immediate postoperative & $18.97 \pm 7.79$ & $29.11 \pm 8.07$ \\
\hline 1 month & $19.05 \pm 8.03$ & $31.34 \pm 8.73$ \\
\hline 3 month & $19.23 \pm 8.77$ & $33.68 \pm 7.85$ \\
\hline 6 month & $19.51 \pm 8.02$ & $33.94 \pm 8.67$ \\
\hline 12 month & $19.87 \pm 8.34$ & $35.07 \pm 9.10$ \\
\hline \multicolumn{3}{|c|}{ Relative anterior vertebral height (\%) } \\
\hline Immediate postoperative & $92.42 \pm 5.14$ & $71.21 \pm 4.83$ \\
\hline 1 month & $92.21 \pm 4.49$ & $68.88 \pm 5.01$ \\
\hline 3 month & $91.75 \pm 6.44$ & $66.35 \pm 5.94$ \\
\hline 6 month & $91.69 \pm 5.02$ & $63.81 \pm 6.23$ \\
\hline 12 month & $91.58 \pm 5.34$ & $61.72 \pm 6.96$ \\
\hline \multicolumn{3}{|c|}{ Relative central vertebral height (\%) } \\
\hline Immediate postoperative & $79.74 \pm 3.92$ & $60.53 \pm 3.31$ \\
\hline 1 month & $79.19 \pm 3.88$ & $58.91 \pm 3.56$ \\
\hline 3 month & $78.77 \pm 4.07$ & $58.21 \pm 3.87$ \\
\hline 6 month & $78.65 \pm 3.98$ & $57.37 \pm 3.61$ \\
\hline 12 month & $78.31 \pm 4.11$ & $56.96 \pm 3.71$ \\
\hline \multicolumn{3}{|l|}{ KA $\left(^{\circ}\right)$} \\
\hline Immediate postoperative & $7.11 \pm 3.01$ & $10.89 \pm 2.91$ \\
\hline 1 month & $7.73 \pm 3.11$ & $11.56 \pm 3.34$ \\
\hline 3 month & $7.78 \pm 2.89$ & $11.88 \pm 2.85$ \\
\hline 6 month & $7.85 \pm 3.08$ & $11.96 \pm 3.41$ \\
\hline 12 month & $8.01 \pm 3.67$ & $12.47 \pm 3.28$ \\
\hline
\end{tabular}

studies demonstrated that better diffusion of cement distributes the load of the fractured vertebrae [35, 36]. Breaking the peripheral membrane, filling the cleft, and making the cement be interdigitated with the surrounding cancellous bone are the key point to pain relief and preventing further collapse [37]. However, the needle tip in previous study was still traditionally placed in the IVC area and lacks accurate navigation and guidance.

Therefore, we combined MR technology with the real patient in order to achieve accurate navigation to IVC area of OVCF. Mixed reality (MR) is a technology that divorces digital reality and virtual digital images from the virtual world on the screen, so that three-dimensional virtual objects and the real world can be accurately combined, which enables accurate replication of patient anatomy. Using the presented methodology, patient anatomy and surgical instruments can be aligned correctly in spatial relation to each other [38, 39]. Combining 3D reconstruction and MR technology is a new mode of production, which is applied in many fields because of the advantages of visualization, plasticity, and rapid printing [40-42]. Moreover, it can also help surgeons to achieve accurate navigation and position in spinal surgery [43, 44].

In our study, the location of IVC in the vertebral body could be accurately acquired in CAD anatomic images preoperatively as a result of fusion of MRI and three-dimensional CT images, and the CAD virtual digital images could be accurately combined with the patient's body during operation, which was a great advantage for the guidance. Combined with $\mathrm{C}$-arm fluoroscopic images during surgery, MR technology could assist surgeons to acquire real-time and accurate guidance to the IVC area, reducing operation time and numbers of $\mathrm{C}$-arm fluoroscopy and increasing the accuracy and efficacy of surgery.

Our study also demonstrates that mixed reality (MR) technology can change the bottleneck of unarmed puncture in IVC-PKP surgery. The vertebra can be reconstructed and restored by three-dimensional $\mathrm{CT}$ reconstruction before operation, so that the location of 
IVC lesions can be displayed more intuitively in front of doctors. During the operation, the surgeons wore HoloLens glasses and obtained holographic image information, so that the patient's virtual 3D digital model overlapped completely with the patient's lesion site; thus, the doctor has a new way of operation [45].

With the assistance of MR in our study, the accuracy of puncture was significantly higher than that of traditional methods during the PKP procedure, especially in some patients with lesions of the vertebrae. The vertebral body may be accompanied by mild lateral bending, rotation, the formation of a bridge, and so on, which increase the difficulty of the operation, and the entry point and direction are difficult to control, especially in patients with IVC. Combined with MR, it can assist virtual positioning, give doctors the correct positioning point and direction when punctured, make the procedure more accurate and safer, is easy to operate, and obviously reduce the number of fluoroscopy and operation time. Elmi-terander et al. [46] confirmed that combined with intraoperative 3D image, navigation technology is expected to replace intraoperative X-ray or fluoroscopy in the process of thoracolumbar pedicle puncture and has high accuracy and safety.

Our study also indicates that the number of X-ray irradiation of $\mathrm{C}$-arm machine in MR-PKP group was significantly lower than that in the traditional group. In the past, $\mathrm{C}$-arm machine was needed to judge the position of the needle many times during operation, which was harmful to doctors. However, with MR navigation technology, the number of $\mathrm{C}$-arm machine used in operation could be significantly reduced, and the injury to doctors and patients could also be obviously reduced.

In our study, we also found that the amount of cement injected and relative vertebral height in the MR-assisted group increased more compared with the control group. The presence of the peripheral membrane may prevent the diffusion of cement; thus, some part of the vertebra cannot be filled with cement [47], leading to the smaller volume injected in group B (Fig. 1f). The vertebral height was reconstructed by balloon and prone postural reduction, without sufficient cement reinforcing, especially touching both endplates; the vertebral height in group B may not be maintained and might be lost after operation [47-49]. Daisuke et al. [50] have reported that increased cement injection may be due to the increased balloon expansions, and this increased amount of cement injection may affect postoperative vertebral height improvement.

However, delayed reaction, small field of vision, dim brightness, and insufficient stability of binocular shared vision of MR technology inevitably lead to the need of $\mathrm{C}$-arm fluoroscopy assistance. In the specialized softand hardware, the cost was relatively higher.

\section{Conclusion}

In conclusion, MR technology was adopted as an efficient method for navigation and position. Compared with the traditional procedure of PKP, it acquired an accurate position of IVC in OVCF and preferable clinical outcomes. We consider this technology as a perfect approach for guidance in minimally invasive surgery.

\section{Limitations}

1. This research lacks of biomechanical study, and the sample size is too small; this also needs long-term follow-up and research.

2. Although with fused CAD anatomic images preoperatively, MR technology cannot acquire realtime MRI images of IVC during operation.

3. For the disadvantages of delayed reaction, small field of vision, dim brightness, and insufficient stability of binocular shared vision, MR technology still needs $\mathrm{C}$-arm fluoroscopy assistance.

\section{Abbreviations}

BMD: Bone mineral density; CAD: Computer aided design; CT: Computed tomography; IVC: Intravertebral vacuum cleft; KA: Kyphotic angle; MR: Mixed reality; MRI: Magnetic resonance imaging; ODI: Oswestry Disability Index; OVCF: Osteoporotic vertebral compression fracture; PKP: Percutaneous kyphoplasty; PMMA: Poly methyl methacrylate; VAS: Visual analog scale

\section{Acknowledgements}

We would like to thank all the participants who took part in this research for their time and help.

\section{Statement}

Our study adheres to CONSORT guidelines, and a completed CONSORT checklist was submitted as an additional file.

\section{Authors' contributions}

PW, QY, and LW conceived and designed the experiment. PW and YG collected the patient samples. PW and $\mathrm{HZ}$ analyzed and interpreted the data. PW prepared the manuscript. LW, YX, and QY reviewed the manuscript. PW, $H Z, Q Y$, and $L W$ are responsible for the integrity of the data. LW approved the final version of the manuscript. All authors have read and approved the final submitted manuscript.

\section{Funding}

Not funded.

\section{Availability of data and materials}

The datasets used and/or analyzed during the current study are available from the corresponding author on reasonable request.

\section{Ethics approval and consent to participate}

This study was approved by the ethics committee of Nanjing First Hospital. Written informed consent was obtained from all patients.

\section{Consent for publication}

Not applicable.

Competing interests

The authors declare that they have no competing interests. 
Received: 6 May 2019 Accepted: 30 July 2019

Published online: 08 August 2019

\section{References}

1. Bonnard E, Foti P, Kastler A, Amoretti N. Percutaneous vertebroplasty under local anaesthesia: feasibility regarding patients' experience. Eur Radiol. 2016; 27:1512-6.

2. Mathis JM, Barr JD, Belkoff SM, et al. Percutaneous vertebroplasty: a developing standard of care for vertebral compression fractures. Am J Neuroradiol. 2001;22:373-81.

3. Diamond $\mathrm{TH}$, Champion $\mathrm{B}$, Clark WA. Management of acute osteoporotic vertebral fractures: a nonrandomized trial comparing percutaneous vertebroplasty with conservative therapy. Am J Med. 2003;114:257-65.

4. Do HM, Kim BS, Marcellus ML, et al. Prospective analysis of clinical outcomes after percutaneous vertebroplasty for painful osteoporotic vertebral body fractures. AJNR Am J Neuroradiol. 2005;26:1623-8.

5. Voormolen MHJ, Mali WPTM, Lohle PNM, et al. Percutaneous vertebroplasty compared with optimal pain medication treatment: short-term clinical outcome of patients with subacute or chronic painful osteoporotic vertebral compression fractures. The VERTOS study. AJNR Am J Neuroradiol. 2007;28:555-60.

6. Clarençon F, Fahed R, Gabrieli J, et al. Safety and clinical effectiveness of percutaneous vertebroplasty in the elderly ( $\geq 80$ years). Eur Radiol. 2016;26:2352-8.

7. Kim YJ, Lee JW, Kim KJ, Chung SK, Kim HJ, Park JM, Kang HS. Percutaneous vertebroplasty for intravertebral cleft: analysis of therapeutic effects and outcome predictors. Skeletal Radiol. 2010;39:757-66.

8. Kim YC, Kim YH, Ha KY. Pathomechanism of intravertebral clefts in osteoporotic compression fractures of the spine. Spine J. 2014;14:659-66.

9. Linn J, Birkenmaier C, Hoffmann RT, Reiser M, Baur-Melnyk A. The intravertebral cleft in acute osteoporotic fractures: fluid in magnetic resonance imagingvacuum in computed tomography? Spine. 2009;34:E88-93.

10. Zhang J, He X, Fan Y, Du J, Hao D. Risk factors for conservative treatment failure in acute osteoporotic vertebral compression fractures (OVCFs). Arch Osteoporos. 2019;14:24.

11. Sasaki Y, Aoki Y, Nakajima A, Shibata Y, Sonobe M, Takahashi K, et al. Delayed neurologic deficit due to foraminal stenosis following osteoporotic late collapse of a lumbar spine vertebral body. Case Reports in Orthopedics. 2013:2013:1-5.

12. Ito $Y$, Hasegawa $Y$, Toda K, Nakahara S. Pathogenesis and diagnosis of delayed vertebral collapse resulting from osteoporotic spinal fracture. Spine J. 2002;2:101-6.

13. Ha KY, Lee JS, Kim KW, et al. Percutaneous vertebroplasty for vertebral compression fractures with and without intravertebral clefts. J Bone Joint Surg Br. 2006;88:629-33.

14. Koh YH, Han D, Cha JH, Seong CK, Kim J, Choi YH. Vertebroplasty: magnetic resonance findings related to cement leakage risk. Acta Radiologica. 2007; 48(3):315-20.

15. Heo DH, Chin DK, Yoon YS, Kuh SU. Recollapse of previous vertebral compression fracture after percutaneous vertebroplasty. Osteoporosis International. 2009;20(3):473-80

16. Li KC, Wong TU, Kung FC, Li A, Hsieh CH. Staging of Kümmell's disease. J Musculoskelet Res. 2004;8(01):13.

17. Wu AM, Ni WF, Weng W, Chi YL, Xu HZ, Wang XY. Outcomes of percutaneous kyphoplasty in patients with intravertebral vacuum cleft. Acta Orthop Belg. 2012;78:790-5.

18. Kim YY, Rhyu KW. Recompression of vertebral body after balloon kyphoplasty for osteoporotic vertebral compression fracture. Eur Spine J. 2010;19(11):1907-12

19. Nicola S, Stoicu-Tivadar L. Mixed reality supporting modern medical education. Stud Health Technol Inform. 2018;255:242-6.

20. Eck U, Winkler A. Display technologies for augmented reality in medical applications. Unfallchirurg. 2018;121:278-85.

21. Bova FJ, Rajon DA, Friedman WA, Murad GJ, Hoh DJ, Jacob RP, Lampotang S, Lizdas DE, Lombard G, Lister JR. Mixed-reality simulation for neurosurgical procedures. Neurosurg. 2013:138-45.

22. Sappenfield JW, Smith WB, Cooper LA, et al. Visualization improves supraclavicular access to the subclavian vein in a mixed reality simulator. Anesth Analg. 2018;127(1):83-9.

23. Lee SC, Fuerst B, Tateno K, et al. Multi-modal imaging, model-based tracking, and mixed reality visualisation for orthopaedic surgery. Healthc Technol Lett. 2017;4(5):168-73.
24. Fischer M, Fuerst B, Lee SC, et al. Preclinical usability study of multiple augmented reality concepts for K-wire placement. Int J Comput Assist Radiol Surg. 2016;11(6):1007-14.

25. Limthongkul W, Karaikovic EE, Savage JW, Markovic A. Volumetric analysis of thoracic and lumbar vertebral bodies. Spine J. 2010;10:153-8.

26. Kawaguchi S, Horigome K, Yajima H, et al. Symptomatic relevance of intravertebral cleft in patients with osteoporotic vertebral fracture. J Neurosurg Spine. 2010;13:267-75.

27. Fang $X, Y u F$, Fu S, Song $H$. Intravertebral clefts in osteoporotic compression fractures of the spine: incidence, characteristics, and therapeutic efficacy. Int J Clin Exp Med. 2015;8(9):16960.

28. Liang Z, Qiang W, Lin W, Jian S, Qiwei Z, Changtai S. Bone cement distribution in the vertebral body affects chances of recompression after percutaneous vertebroplasty treatment in elderly patients with osteoporotic vertebral compression fractures. Clin Interv Aging. 2017; $12: 431-6$

29. Gaughen JR, Jensen ME, Schweickert PA, Marx WF, Kallmes DF. The therapeutic benefit of repeat percutaneous vertebroplasty at previously treated vertebral levels. AJNR Am J Neuroradiol. 2002; 23(10):1657-61

30. Kim YJ, Chae SU, Kim GD, Park KH, Lee YS, Lee HY. Radiographic detection of osteoporotic vertebral fracture without collapse. J Bone Metab. 2013;20(2).

31. Knavel EM, Rad AE, Thielen KR, Kallmes DF. Clinical outcomes with hemivertebral filling during percutaneous vertebroplasty. AJNR Am J Neuroradiol. 2009;30(3):496.

32. Wu AM, Chi YL, Ni WF. Vertebral compression fracture with intravertebral vacuum cleft sign: pathogenesis, image, and surgical intervention. Asian Spine J. 2013;7(2):148-55.

33. Becker S, Tuschel A, Chavanne A, Meissner J, Ogon M. Balloon kyphoplasty for vertebra plana with or without osteonecrosis. J Orthop Surg. 2008;16(1):14-9.

34. Ishiyama M, Numaguchi Y, Makidono A, Kobayashi N, Fuwa S, Ohde S, et al. Contrast-enhanced MRI for detecting intravertebral cleft formation: relation to the time since onset of vertebral fracture. Am J Roentgenol. 2013;201(1):W117-23

35. Erbe EM, Clineff TD, Gualtieri G. Comparison of a new bisphenol-a-glycidyl dimethacrylate-based cortical bone void filler with polymethyl methacrylate. Eur Spine J. 2001:10:S147-52.

36. Bae H, Hatten HP, Linovitz R, Tahernia AD, Schaufele MK, Mccollom V, et al. A prospective randomized FDA-IDE trial comparing Cortoss with PMMA for vertebroplasty: a comparative effectiveness research study with 24-month follow-up. Spine. 2012;37(7):544-50.

37. NNiu J, Zhou H, Meng Q, Shi J, Meng B, Yang H. Factors affecting recompression of augmented vertebrae after successful percutaneous balloon kyphoplasty: a retrospective analysis. Acta Radiol. 2014. https://doi. org/10.1177/0284185114556016.

38. Torres I, De Luccia N. A simulator for training in endovascular aneurysm repair: the use of three dimensional printers. Eur J Vasc Endovasc Surg. 2017:54(2):247-53.

39. Stefan P, Habert S, Winkler A, Lazarovici M, Fürmetz J, Eck U, Navab $\mathrm{N}$. A radiation-free mixed-reality training environment and assessment concept for C-arm-based surgery. Int J Comput Assist Radiol Surg. 2018:13:1335-44

40. Wu AM, Wang S, Weng WQ, Shao ZX, Yang XD, Wang JS, et al. The radiological feature of anterior occiput-to-axis screw fixation as it guides the screw trajectory on 3D printed models: a feasibility study on 3D images and 3D printed models. Medicine. 2014;93(28):e242.

41. Wu AM, Shao ZX, Wang JS, Yang XD, Weng WQ, Wang XY, Xu HZ, Chi YL, Lin ZK. The accuracy of a method for printing three-dimensional spinal models. PLoS ONE. 2015;10:e0124291.

42. Maruthappu M, Keogh B. (2014) How might 3D printing affect clinical practice?. BMJ, 349 (dec30 1), g7709-g7709.

43. Sugawara T, Higashiyama N, Kaneyama S, Sumi M. Accurate and simple screw insertion procedure with patient-specific screw guide templates for posterior C1-C2 fixation. Spine. 2016;42(6):1.

44. Liu K, Zhang Q, Li X, Zhao C, Quan X, Zhao R, et al. (2016) Preliminary application of a multi-level 3D printing drill guide template for pedicle screw placement in severe and rigid scoliosis. European Spine Journal.

45. Ghanai S, Marmulla R, Wiechnik J, et al. Computer-assisted three -dimensional surgical planning: 3D virtual articulator: technical note. Int J Oral Maxillofac Surg. 2010;39(1):75-82. 
46. Terander AE, Nachabe R, Skulason H, Pedersen K, Edström E. Feasibility and accuracy of thoracolumbar minimally invasive pedicle screw placement with augmented reality navigation technology. Spine. 2017;43(14):1.

47. Clark W, Bird P, Gonski P, Diamond TH, Smerdely P, McNeil HP, Schlaphoff G, Bryant C, Barnes E, Gebski V. Safety and efficacy of vertebroplasty for acute painful osteoporotic fractures (VAPOUR): a multicentre, randomised, doubleblind, placebo-controlled trial. Lancet. 2016;388:1408-16.

48. Chen YJ, Chen HY, Lo DF, Chen HT, Hsu HC. Kirschner wire-guided technique for inserting a second needle into inadequately filled vertebrae in vertebroplasty: a technical report. Spine J. 2014;14:3025-9.

49. Chen YJ, Chen WH, Chen HT, Hsu HC. Repeat needle insertion in vertebroplasty to prevent re-collapse of the treated vertebrae. Eur J Radiol. 2012;81:558-61.

50. Daisuke U, Yu Y, Yasuhiro N, et al. Balloon kyphoplasty under threedimensional radiography guidance. Neurologia medico-chirurgica. 2017; 57(9):489-95.

\section{Publisher's Note}

Springer Nature remains neutral with regard to jurisdictional claims in published maps and institutional affiliations.

Ready to submit your research? Choose BMC and benefit from:

- fast, convenient online submission

- thorough peer review by experienced researchers in your field

- rapid publication on acceptance

- support for research data, including large and complex data types

- gold Open Access which fosters wider collaboration and increased citations

- maximum visibility for your research: over $100 \mathrm{M}$ website views per year

At BMC, research is always in progress.

Learn more biomedcentral.com/submissions 